\title{
Isolation of bioactive compounds of Clausena anisata (Willd.) Hook. growing in South Africa by liquid chromatography-mass spectroscopy profiling, and their antibacterial activities
}

\begin{tabular}{|c|c|}
\hline \multicolumn{2}{|c|}{$\begin{array}{l}\text { Authors: } \\
\text { Ibraheem O. Lawal }{ }^{1} \text { @ } \\
\text { Mustapha Galadima } \\
\text { Paul O. Ogunbamowo }\end{array}$} \\
\hline \multicolumn{2}{|c|}{$\begin{array}{l}\text { Affiliations: } \\
{ }^{1} \text { Biomedicinal Research } \\
\text { Centre, Forestry Research } \\
\text { Institute, Nigeria }\end{array}$} \\
\hline \multicolumn{2}{|c|}{$\begin{array}{l}{ }^{2} \text { Faculty of Pure and Applied } \\
\text { Sciences, University of } \\
\text { Huddersfield, United } \\
\text { Kingdom }\end{array}$} \\
\hline \multicolumn{2}{|c|}{$\begin{array}{l}\text { Corresponding author: } \\
\text { Ibrahim Lawal, } \\
\text { ibroodula@yahoo.com }\end{array}$} \\
\hline \multicolumn{2}{|c|}{$\begin{array}{l}\text { Dates: } \\
\text { Received: } 15 \text { May } 2017 \\
\text { Accepted: } 09 \text { Mar. } 2018 \\
\text { Published: } 26 \text { June } 2018\end{array}$} \\
\hline \multicolumn{2}{|c|}{$\begin{array}{l}\text { How to cite this article: } \\
\text { Lawal, I.O., Galadima, M. \& } \\
\text { Ogunbamowo, P.O., 2018, } \\
\text { 'Isolation of bioactive } \\
\text { compounds of Clausena } \\
\text { anisata (Willd.) Hook. } \\
\text { growing in South Africa by } \\
\text { liquid chromatography-mass } \\
\text { spectroscopy profiling, and } \\
\text { their antibacterial activities', } \\
\text { Journal of Medicinal Plants } \\
\text { for Economic Development } \\
\text { 2(1), a22. https://doi. } \\
\text { org/10.4102/jomped.v2i1.22 }\end{array}$} \\
\hline \multicolumn{2}{|c|}{$\begin{array}{l}\text { Copyright: } \\
\text { (c) 2018. The Authors. } \\
\text { Licensee: AOSIS. This work } \\
\text { is licensed under the } \\
\text { Creative Commons } \\
\text { Attribution License. }\end{array}$} \\
\hline \multicolumn{2}{|l|}{ Read onlin } \\
\hline 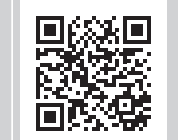 & $\begin{array}{l}\text { Scan this QR } \\
\text { code with your } \\
\text { smart phone or } \\
\text { mobile device } \\
\text { to read online. }\end{array}$ \\
\hline
\end{tabular}

Clausena anisata possesses several ethnopharmacological properties. It is used for the treatment of several diseases and health conditions, including oxidative stress and respiratory infections. This study was aimed at isolating and validating the potency of some bioactive compounds in this plant using Fourier transform infrared spectroscopy, liquid chromatography-mass spectroscopy and nuclear magnetic resonance techniques. A bioautography method was used for the antibacterial assay. Quercetin 3,4'-dimethyl ether was identified with a molecular mass of $330.2288 \mathrm{Da}$ at a retention time of 0.72 , clausine B was identified at a retention time of 24.31 and 24.37 with a molecular mass of $271.0844 \mathrm{Da}$, clausenocoumarine was identified at a retention time of 5.42 with a molecular weight of $366.1011 \mathrm{Da}$, while terpineol was also identified with the inhibition of the growth of the test organisms (Escherichia coli, Staphylococcus aureus and Subtilis cereus) to quercetin 3,4'-dimethyl ether, clausine B and clausenocoumarin observed at Rf values of $0.24,0.52$ and 0.54 , respectively, on the plate using hexane/ethyl acetate (2:1) as mobile phase. A novel enantiomer of anisocoumarin derivatives and three known compounds were isolated and identified from a fraction showing a single band in the acetone leaf extract of C. anisata. Their chemical compounds were elucidated by nuclear magnetic resonance. The pharmacological potency of these compounds was discussed.

\section{Introduction}

The emergence of several ailments, health conditions and other diseases, including Ebola virus, human immunodeficiency virus (HIV or AIDS), diabetes, arthritis, microbial infections and tuberculosis have posed a great threat to human health. Medicinal plants can be described as any plant organ that possesses therapeutic indications to alleviate symptoms of diseases and conditions in human and animals; therefore, herbalists rely on medicinal plants and are known with prescription of herbal remedy either singularly or in combination depending on the condition, of the patients for categories of diseases and/or infections (Watt \& Breyer-Brandwijk 1962). In South Africa, the use of medicinal plants has a very long history in the management of diseases and ailments; the use of plants has a positive influence on primary healthcare in the communities (Amoo et al. 2009; Grierson \& Afolayan 1999). Previous studies in the Eastern Cape Province have substantiated the fact that the local inhabitants still believe strongly in the holistic nature of treatments (Lawal, Grierson \& Afolayan 2014; Van Wyk \& Wink 2004). Some researchers have estimated that $60 \%$ of the South African population uses medicinal plants, with an estimated dosage of $750 \mathrm{~g}$ annually (Masoko \& Nxumalo 2013; Moeng 2010). Considering the number of people using medicinal plants, the search for new pharmacologically-active compounds with a standardised dosage is imperative.

It is an established fact that drug-resistant bacteria are causative agents of long-standing infections or diseases; pathogenic bacteria have become increasingly drug resistant and, more often than not, these are the cause of premature death (Dubey et al. 2011). Among the ones of most concern are methicillin-resistant Staphylococcus aureus and a multidrug-resistant Escherichia coli that was reported to have a major clonal complex and has resistance to 23 antibiotics (Maple, Hamilton-Miller \& Brumfitt 1989). Gram-positive pathogens responsible for respiratory infections include Bacillus cereus, Enterococcus faecalis, S. aureus and Streptococcus pyogenes while common Gram-negative pathogens associated with respiratory infections include Pseudomonas aeruginosa (Van Vuuren 2007). 
Clausena anisata (Willd.) Hook. is a shrub that belongs to the Rutaceae family; it is characterised by evergreen leaves and is the only species in Africa out of the 15 species of its genus. The various morphological parts of the plant have been identified to be effective remedies against worm infections, respiratory ailments, heart disorders, hypertension, malaria, fever, rheumatism, insanity, convulsion and other inflammatory conditions (Hamza, van den Bout-van den Beukel \& Matee 2006; Hutchings et al. 1996). The concoction of the stem bark and the leaves was also identified to be an effective traditional treatment for tuberculosis during an ethnobotanical survey among Xhosa people in the Eastern Cape Province (Lawal et al. 2014). The unsustainable harvesting of this shrub, because of its large range of medicinal properties, could perhaps threaten its existence. However, C. anisata is classified as a red list plant in South Africa (Raimondo 2009). The essential oil in C. anisata has been reported to be responsible for its several pharmacological activities, including antimicrobial, anti-inflammatory and antidiabetic properties (Ojewole 2002; Senthikumar \& Venkatesalu 2009; York et al.)

Some researchers, for instance, Senthikumar and Venkatesalu (2009), Chakraborty et al. (1995) and Songue et al. (2014), have reported on isolated compounds from $C$. anisata root, leaves and stem bark, including carbazole alkaloids, clausenol, coumarins, limonoids, reducing sugars and essential oils, including the $\beta$-pinene and sabinene chemotypes. The antimicrobial properties of the plant have been reported in Ghana (Agyepong et al. 2014), Cameroon (Songue et al. 2014) and KwaZulu-Natal, South Africa (York, van Vuuren \& De Wet 2012). However, there is scant information on the antibacterial activities of this plant in Eastern Cape Province, while the liquid chromatographymass spectroscopy (LC-MS) profiling of the compounds identified and their antibacterial properties are reported in this study for the first time. A new compound was also identified and elucidated using nuclear magnetic resonance (NMR). The aim of this study was to evaluate scientifically the pharmacological potency of the identified and isolated compounds.

\section{Materials and methods}

\section{Equipment}

An SPL 16 with UPF horizontal shaker (Labcon, Petaluma, CA, USA) was used for preparing the solvent extracts. A rotary evaporator (Buchi, Flawil, Switzerland) was used to evaporate the organic solvent in vacuo. Precision balance 220/C / 2 (RADWAG Instruments, Radom, Poland) were used for weighing milligram and gram quantities. Finnpipettes ${ }^{\mathrm{TM}}$ (Thermo Labsystems, Helsinki, Finland) were used for spiking volumes. Glass pipettes were used for adding extraction solvents. Filter papers (Thermo Labsystems) were used for filtration. Thin-layer chromatography (TLC) plates were purchased from Sigma-Aldrich (Sigma-Aldrich, Johannesburg, South Africa).

\section{Chemicals and reagents}

Acetone, hexane, dichloromethane (DCM), methanol (MeOH), ethyl acetate (EtOAC) and sulphuric acid $\left(\mathrm{H}_{2} \mathrm{SO}_{4}\right)$ were purchased from Merck (Merck, Darmstadt, Germany). Vanillin, 2-(4-Iodophenyl)-3-(4-nitrophenyl)-5-phenyltetrazolium chloride was purchased from Sigma-Aldrich (Johannesburg, South Africa). Distilled water was prepared by a Millipore water system (Milli-QTM, Darmstadt, Germany). Ciprofloxacin and amoxicillin were purchased from Sigma-Aldrich.

\section{Preparation of extracts}

The leaf $(5 \mathrm{~g})$ was extracted with acetone $(50 \mathrm{~mL})$. Acetone was chosen as the solvent in this comparative study because it extracts a range of polar and non-polar compounds (Levy \& Marshall 2004). The mixture was vigorously agitated on a linear shaker and filtered. The filtrate was concentrated to dryness using a rotary evaporator and the residue reconstituted to $50 \mathrm{mg} / \mathrm{mL}$ in acetone.

\section{Qualitative phytochemical screening of the extracts}

The acetone leaf extract was subjected to various qualitative phytochemical tests using various methods (Boye et al. 2012; Omoruyi, Bradley \& Afolayan 2012). The phytochemicals tested were alkaloids, saponins, phytosteroids, phenolics and tannin compounds.

\section{Thin-layer chromatography fingerprints}

TLC plates were loaded with the acetone leaf extracts $(100 \mu \mathrm{g})$ of the leaf, developed using a mobile phase of hexane: $\operatorname{EtOA}_{C}(2: 1),(1: 2)$ and also in acetone only. The plates were each visualised under UV light at $254 \mathrm{~nm}$ and $365 \mathrm{~nm}$ before being sprayed with vanillin-sulphuric acid reagent and heated at $100^{\circ} \mathrm{C}$ for $10 \mathrm{~min}$ until the colour changed. The replicates, which were not sprayed with reagent, were used for the bioautography assay. The retention factor $\left(R_{f}\right)$ values of the separated spots or bands were determined as follows:

$\mathbf{R}_{f}=$ distance travelled by the compound / distance travelled by solvent front

\section{Qualitative antibacterial activity (bioautography)}

A comparison was conducted of the antibacterial chemical components present in the leaves of C. anisata. Acetone extracts of the leaves were analysed on TLC plates using hexane EtOAC (2:1) as mobile phase and then sprayed with S. pyogenes, E. coli and S. aureus; we also developed TLC plates without bacteria. Clear lines show the inhibition of growth of bacteria.

TLC plates were loaded with $20 \mu \mathrm{L}$ of extract, developed in mobile phase. The plates were dried in an oven at $40^{\circ} \mathrm{C}$ for $1 \mathrm{~h}$ to make it free from solvents used to develop the 
chromatograms. The developed bands were sprayed with overnight cultures of E. coli, S. aureus and B. cereus on different TLC plates until completely wet and then were each incubated at $37^{\circ} \mathrm{C}$ in a humidified chamber for $24 \mathrm{~h}$. The plates were sprayed with $\rho$-iodonitrotetrazolium violet (INT) and incubated for an extra $24 \mathrm{~h}$. The presence of clear bands on the plates against a purple background indicated growth inhibition. The bioautography plates were compared with the reference TLC plates prepared (Lekganyane et al. 2012; Masoko \& Nxumalo 2013; Masoko, Picard \& Eloff 2005).

\section{Purification and characterisation of compounds using flash column chromatography and nuclear magnetic resonance}

The acetone leaf extract of $C$. anisata was evaporated to dryness and separated on a flash column filled with silica gel (216 g, 70-230 mesh; Merck), eluted with hexane-EtOA mixtures (in the ratios $1000 \mathrm{~mL}: 100 \mathrm{~mL}, 1600 \mathrm{~mL}: 800 \mathrm{~mL}$ ), $\mathrm{EtOA}_{C}(1000 \mathrm{~mL})$ and finally washed with $\mathrm{MeOH}(1000 \mathrm{~mL})$. Fractions were combined according to their $\mathrm{R}_{f}$ values; a total of seven fractions (A-G) were obtained. Fraction A was singled out for structural elucidation because of the presence of a single band in the TLC. Fraction A was evaporated to dryness and re-dissolved in 100\% acetone, loaded onto glass preparatory plates and developed with hexane: $\operatorname{EtOA}_{C}(2: 1)$ in the glass tank. The final compound was characterised by a $600 \mathrm{MHz}$ Bruker (Rheinstetten, Germany) ${ }^{1} \mathrm{H}$ NMR spectrometer equipped with a $5 \mathrm{~mm}$ dual probe, $\mathrm{CDCL}_{3}$ was used as the solvent and chemical shifts were reported relative to the solvent peaks.

\section{Infrared analysis}

Fourier transform infrared spectroscopy (FT-IR) spectrum was recorded using a Shimadzu (Tokyo, Japan) FT-IR Model 8300 6AD spectrophotometer. The sample (Fractions C, D and $\mathrm{G}$ ) was mixed with potassium bromide pellets $(\mathrm{KBr})$ as a disc and read at a spectral range from $400 \mathrm{~cm}^{-1}$ to $4000 \mathrm{~cm}^{-1}$. The procedures of Shriner et al. (1979) and Al-Maliki (2011) were followed.

\section{Liquid chromatography-mass spectroscopy analysis}

The procedures of Schreiber et al. (2010) were followed for the LC-MS analysis, performed in triplicate and in a randomised order on Fractions C, D and G. Analyses were performed with an Agilent LC-MS system (AB SCIEX, Framingham, MA, USA) Triple TOF 5600) with the analyser and electron spray ionisation source in positive mode. Source parameters were optimised to provide high sensitivity. The source parameters were as follows: gas temperature $600^{\circ} \mathrm{C}$, drying gas flow rate $0.5 \mathrm{~mL} / \mathrm{min}$, nebuliser pressure $50 \mathrm{psi}$, capillary voltage $5500 \mathrm{~V}$, separation was carried out by ultra-high pressure liquid chromatography using a Shimadzu UFLCXR with a Phenomenex (California, USA) Kinetex $2.6 \mu \mathrm{m}(100 \times 2.1)$ column. The mobile phase used was A: water $(5 \mathrm{mM}$ ammonium formate $+0.5 \%$ formic acid) and B (acetonitrile); the gradient program was as follows: 5\% B for starting condition, increase up to $95 \%$ B in $20 \mathrm{~min}$, hold $25 \mathrm{~min}$, increase $\%$ B to $95 \%$ from 2 to $20 \mathrm{~min}$, hold $25.20 \mathrm{~min}$ and decrease $\%$ B to $5 \%$ at the final step. The total run time was $30 \mathrm{~min}$. The injection volume was $50 \mu \mathrm{l}$. The standardised collision energy was $35 \mathrm{~V}$ with collision energy of $\pm 15 \mathrm{~V}$; statistical data processing was carried out using MarkerView software. The detection was accomplished using MS/MS scan mode; compound identification and quantification were performed using PeakView software.

\section{Identification of chemical constituents}

Isolation and identification of compounds in the selected fractions of C. anisata leaf extracts, using the FT-IR, LC-MS and NMR techniques, was achieved by comparison of retention times obtained at identical chromatographic conditions of the analysed fractions; the molecular mass was compared using MS data. Compounds were identified by analysis of the chromatograms using a PeakView library, $\mathbf{R}_{f}$ values, functional group frequency, literature and computer search with the aid of ChemSpider software.

\section{Results and discussion Phytochemical screening}

Phytosteroids, saponins, alkaloids, tannins, phenolics and flavonoids were all present in the acetone leaf extracts of $C$. anisata (Table 1). Plant phenolics including flavonoids, phenols and tannins have been reported for their many medicinal attributes and capability of defending humans against foreign bodies and illness (Dai \& Mumper 2010). With reference to the health benefit significance of plant phenolics to humans, it bears out the relevance of phytochemical content investigation in plant-based research, which is also in line with the view of Masoko and Nxumalo (2013).

\section{Thin-layer chromatography profiling of acetone extract}

TLC has been reported to be one of the best and most appropriate methods for chemical content profiling and a preliminary means for compound evaluation in plants (McGaw, Jager \& Van Staden 2002). TLC of the acetone leaf extract was used as a guide to compare the different fractions obtained during purification using flash column chromatography; the various bands were observed (indicating different constituents and compounds) during daylight with an observation of light green, which indicates the presence of phenols, and light orange, which shows the

TABLE 1: Phytochemical constituents of acetone leaf extract.

\begin{tabular}{lc}
\hline Phytochemical & Acetone extract \\
\hline Phytosteroids & + \\
Saponins & + \\
Alkaloids & + \\
Tannins & + \\
Phenolics & + \\
Flavonoids & + \\
\hline +, present. &
\end{tabular}


TABLE 2: Antibacterial activity of the fractions.

\begin{tabular}{|c|c|c|c|c|c|c|c|c|c|}
\hline \multirow[t]{2}{*}{$\begin{array}{l}\text { Plant or control } \\
\text { drug or fractions }\end{array}$} & \multicolumn{3}{|c|}{ Inhibition diameters (mm) } & \multirow{2}{*}{$\begin{array}{c}\text { Rfs of } \\
\text { compounds in } \\
\text { TLC daylight }\end{array}$} & \multicolumn{2}{|c|}{$\begin{array}{l}\text { Rfs of compounds in } \\
\text { TLC under UV (nM) }\end{array}$} & \multicolumn{3}{|c|}{$\begin{array}{l}\text { Number of active } \\
\text { spots in TLC }\end{array}$} \\
\hline & SP & EC & SA & & 264 & 365 & SP & EC & SA \\
\hline$A$ & - & - & - & 0.94 & - & - & - & - & - \\
\hline B & - & - & - & $0.64,0.74,0.92$ & - & - & - & - & - \\
\hline C & $9 \pm 1.0$ & $6 \pm 0.5$ & $7 \pm 1.0$ & $0.24,0.52,0.7$ & $0.46,0.6$ & $0.12,0.32$ & 2 & 2 & 2 \\
\hline D & $8 \pm 2.0$ & $8 \pm 1.0$ & $8 \pm 1.0$ & $0.2,0.52$ & - & $0.3,0.4$ & 1 & 1 & 1 \\
\hline E & - & - & - & 0.2 & - & - & - & - & - \\
\hline $\mathrm{F}$ & - & - & - & 0.2 & - & - & - & - & - \\
\hline G & $6 \pm 1.5$ & $9 \pm 1.0$ & $9 \pm 1.0$ & $0.2,0.54$ & 0.3 & $0.7,0.33$ & 1 & 1 & 1 \\
\hline Amoxicillin & $12.33 \pm 1.5$ & - & - & - & - & - & - & - & - \\
\hline Ciprofloxacin & $12.33 \pm 0.57$ & - & - & - & - & - & - & - & - \\
\hline
\end{tabular}

Note: Seven fractions were tested, while three fractions were active.

-, not active; SP, Streptococcus pyogenes; EC, Escherichia coli; SA, Staphylococcus aureus; TLC, thin-layer chromatography.

presence of alkaloids (Figures 2 and 3). This was further confirmed, under ultraviolet ray light of $254 \mathrm{~nm}$ and $365 \mathrm{~nm}$, which revealed the presence of phenols with light violet colour under $365 \mathrm{~nm}$ and light green under $254 \mathrm{~nm}$ in Fractions $C$ and $G$, with $R_{f}$ values of 0.46 and 0.40 , respectively, while the fluorescent colour blue was observed in Fraction D, which indicated the presence of alkaloidic compounds, with $\mathbf{R}_{f}$ values of 0.30 and 0.15 (Table 2). This study is in total agreement with the report on isolation and identification of phenols and alkaloids in Elettaria cardamomum under several observations (Al-Maliki 2011). Different spraying reagent was also used to further confirm these compounds, Dragendorff's reagent was used to confirm the presence of alkaloids while the orange colour confirmed the presence of alkaloid compounds in Fractions C and D. Vanillin, and vanillin in $\mathrm{H}_{2} \mathrm{SO}_{4}$, was used to confirm the presence of flavonoids, which was in line with the reports of some researchers, including Al-Maliki (2011), Sasidharan et al. (2011) and Shai \& Eloff (2009)

\section{Bioautography and Fourier transform infrared spectroscopy}

Medicinal herbs constitute the major factors in herbalism and traditional healing practices all over the world. Plants serve as a reservoir for the storage of several classes of compounds; these compounds act as a defence mechanism against foreign bodies and therefore help in the management and cure of several ailments and health conditions in humans and animals. In the isolation process, the choice of solvent for extraction is vital. Some compounds have previously been isolated from the Rutaceae family and C. anisata is one of the species in this family with a similar compound (Figure 1). Some researchers, including Eloff (1999) and Masika and Afolayan (2003), have reported that acetone extracted both polar and non-polar compounds in plants. This is in support of the choice of solvent in this study, while the acetone leaf extract of C. anisata (Fractions C, D and G) was established to possess compounds that showed significant antibacterial activity against the test organisms $S$. aureus, E. coli and $S$. pyogenes compared to the other fractions (A, B, E and F), which showed no activity as revealed in the bioautography assay. Two components in $C$ showed activity against the test organism with $R_{f}$ values of 0.24 ,
0.52 and 0.70 . One component in $\mathrm{D}$ inhibited the test organism with $\mathrm{R}_{f}$ values of 0.20 and 0.52 , while two components in $\mathrm{G}$ also inhibited the growth of the test organism with $\mathrm{R}_{f}$ values of 0.20 and 0.54 . The inhibition diameters of the fractions were also recorded. The fractions showed a relatively higher inhibition zone as compared to standard drugs (amoxicillin and ciprofloxacin) (Table 2). The effectiveness of the fractions obtained from acetone extracts corroborates with a similar antimicrobial study on Curtisia dentata growing in South Africa, while the compounds isolated from the acetone leaf extract showed significant inhibition against some microorganisms (Shai \& Eloff 2009). Overall, the highest activity on the test organism was observed with Fractions D and G with inhibition diameters of $8 \pm 2.0$ and $6 \pm 1.5$ against $S$. pyogenes as compared to the standard drugs. Although antibacterial activities have been reported in other countries for C. anisata, for instance India, Ghana and in KwaZulu-Natal Province of South Africa (Agyepong et al. 2014; Parekh, Jadeja \& Chanda 2005; York et al. 2012), this could justify its folkloric usage as one of the plants in the Eastern Cape for treating respiratory infections, including tuberculosis, as previously reported (Buwa \& Afolayan 2009; Lawal et al. 2014).

From the FT-IR chromatograms of the isolated alkaloid compounds, for Fraction $\mathrm{C}$ there was indication of a strong band at $1719 \mathrm{~cm}^{-1}$ belonging to the $(\mathrm{C}=\mathrm{O}) \alpha, \beta$ unsaturated ester group of alkaloids, while strong bands at $726 \mathrm{~cm}^{-1}$ belonging to an aromatic group $(\mathrm{C}-\mathrm{H})$ were observed, as was a broad band $\left(3632 \mathrm{~cm}^{-1}\right)$ representing the stretching vibration of a phenolic or alcoholic $(\mathrm{OH})$ group with the hydrogen bonding. The two medium bands at $2725 \mathrm{~cm}^{-1}$ and $2940 \mathrm{~cm}^{-1}$ represent aliphatic $\mathrm{C}-\mathrm{H}$; aldehyde/ketone group $(\mathrm{H}-\mathrm{C}=\mathrm{O}: \mathrm{C}-\mathrm{H}),(\mathrm{C}-\mathrm{H}$ rock and $\mathrm{C}-\mathrm{H}$ bend) alkanes at $1370 \mathrm{~cm}^{-1}$ and $1455 \mathrm{~cm}^{-1}$ were also observed in the chromatograms. The medium band at $1157 \mathrm{~cm}^{-1}$ confirms the alkaloidic stretch of aliphatic amine $(\mathrm{C}-\mathrm{N})$. Fraction D revealed a sharp band at $3631 \mathrm{~cm}^{-1}$ representing $(\mathrm{O}-\mathrm{H})$ stretch free hydroxyl groups of alcohol or phenols, while a medium band of $3160 \mathrm{~cm}^{-1}$ representing $(\mathrm{O}-\mathrm{H})$ stretch of carboxylic acids was observed; at $2726 \mathrm{~cm}^{-1}$ and $2945 \mathrm{~cm}^{-1}$ a medium stretch of aldehyde $(\mathrm{H}-\mathrm{C}=\mathrm{O}: \mathrm{C}=\mathrm{O}-)$ and alkanes group $(\mathrm{C}-\mathrm{H})$ were 
<smiles>O=C1CC(c2ccc(O)cc2)Oc2cc(O)ccc21</smiles>

7-Hydroxy-2-(4-hydroxyphenyl)chroman-4-one

\section{A: Flavanone}<smiles>O=c1cc(-c2ccc(O)cc2)oc2cc(O)c(O)cc12</smiles>

6,7-Dihydroxy-2-(4-hydroxyphenyl)-4H-chromen-4-one

C: Flavone<smiles>O=c1c(O)c(-c2ccc(O)cc2)oc2cc(O)cc(O)c12</smiles>

3,5,7-Trihydroxy-2-(4-hydroxyphenyl)-4H-chromen-4-one

\section{E: Flavonol}<smiles>O=c1ccc2ccccc2o1</smiles>

2H-chromen-2-one

B: Coumarin<smiles>O=c1c(-c2ccc(O)cc2)coc2cc(O)cc(O)c12</smiles>

5,7-Dihydroxy-3-(4-hydroxyphenyl)-4H-chromen-4-one<smiles>Oc1ccc(-c2[o+]c3cc(O)cc(O)c3cc2O)cc1</smiles>

3,5,7-Trihydroxy-2-(4-hydroxyphenyl)chromenylium

F: Anthocyanidin

Source: Eloff 1998

FIGURE 1: Structure of some secondary metabolites in the Rutaceae family.

also observed. The alkane groups of $\mathrm{C}-\mathrm{H}$ rock and $\mathrm{C}-\mathrm{H}$ bend at $1370 \mathrm{~cm}^{-1}$ and $1455 \mathrm{~cm}^{-1}$ were also represented. A medium stretch of aliphatic amine $(\mathrm{C}-\mathrm{N})$ was indicated at $1071 \mathrm{~cm}^{-1}$, reflecting the presence of an alkaloidic compound. Fraction G affirms the presence of phenols (flavonoid) at the strong stretch of free hydroxyl of phenol or alcohol with the frequency of $3622 \mathrm{~cm}^{-1}$, which represented the stretching vibration of hydrogen bonding, indicating the presence of the flavonoid. The frequencies $2923 \mathrm{~cm}^{-1}$ and $2725 \mathrm{~cm}^{-1}$ represent groups of medium stretch alkanes $(\mathrm{C}-\mathrm{H})$ and aldehyde $(\mathrm{H}-\mathrm{C}-\mathrm{C}=\mathrm{O}: \mathrm{C}-\mathrm{H})$, respectively, while the frequency of $1653 \mathrm{~cm}^{-1}$ represents a medium stretch of the alkene group $(-C=C)$. This study is in line with a similar study on the identification of

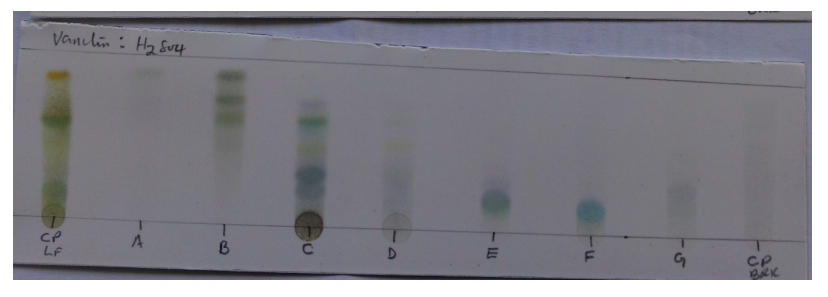

FIGURE 2: Comparison of chemical components present in leaves of Clausena anisata (Fractions A-G). Thin-layer chromatography plates were developed in hexane: EtOAC (2:1) and sprayed with vanillin-sulphuric acid.

alkaloids and phenolic compounds and their functional groups frequencies predetermining the classes and group of compounds in medicinal plants (Al-Maliki 2011; Rashed \& Butnariu 2014). 


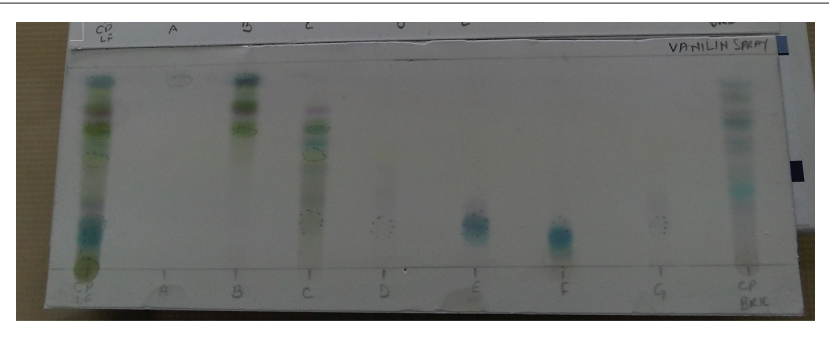

FIGURE 3: Comparison of chemical components present in leaves of $C$. anisato (Fractions $A-G)$. Thin-layer chromatography plates were developed in hexane: EtOAC (2:1) and sprayed with vanillin only.

TABLE 3: Elucidation and characterisation of 5,7-disubstituted coumarin derivatives $4 \mathrm{a}$ and $4 \mathrm{~b}$ using ${ }^{1} \mathrm{H}$ NMR $\left(\mathrm{CDCl}_{3}, 600 \mathrm{MHz}\right.$ ) (spectral data).

\begin{tabular}{|c|c|c|}
\hline Number & $\delta_{H \text { ppm (4a) }}$ & $\delta_{\mathrm{H} \mathrm{ppm} \mathrm{(4b)}}$ \\
\hline 1 & - & - \\
\hline 2 & - & - \\
\hline 3 & - & - \\
\hline 4 & $8.00(\mathrm{~s} 1 \mathrm{H})$ & $8.00(\mathrm{~s} 1 \mathrm{H})$ \\
\hline $4 a$ & - & - \\
\hline 5 & - & - \\
\hline 6 & $7.55(\mathrm{~d}, J=3.6 \mathrm{~Hz})$ & $7.56(\mathrm{~d}, J=2.4 \mathrm{~Hz})$ \\
\hline 7 & - & - \\
\hline 8 & $7.72(\mathrm{~d}, J=3.6 \mathrm{~Hz}, 1 \mathrm{H})$ & $7.73(\mathrm{~d}, J=3.6 \mathrm{~Hz}, 1 \mathrm{H})$ \\
\hline $8 a$ & - & - \\
\hline $1^{\prime}$ & $2.28(\mathrm{~d}, J=6.9 \mathrm{~Hz}, 1 \mathrm{H})$ & $2.28(\mathrm{~d}, J=6.9 \mathrm{~Hz}, 1 \mathrm{H})$ \\
\hline $2^{\prime}$ & $5.10(\mathrm{~s}, \mathrm{OH})$ & $5.10(\mathrm{~s}, \mathrm{OH})$ \\
\hline $2^{\prime}$ & $5.35(\mathrm{~s}, 1 \mathrm{H})$ & $5.25(\mathrm{~s}, 1 \mathrm{H})$ \\
\hline $3^{\prime}$ & $5.55(\mathrm{~s}, \mathrm{OH})$ & $5.55(\mathrm{~s}, \mathrm{OH})$ \\
\hline $4^{\prime}$ & - & - \\
\hline $5^{\prime}$ & $5.70(\mathrm{~s}, 1 \mathrm{H})$ & $5.70(\mathrm{~s}, 1 \mathrm{H})$ \\
\hline $6^{\prime}$ & - & - \\
\hline $7^{\prime}$ & $1.88\left(\mathrm{~s}, 3 \mathrm{H}=\mathrm{CH}_{3}\right)$ & $1.88\left(\mathrm{~s}, 3 \mathrm{H}=\mathrm{CH}_{3}\right)$ \\
\hline $8^{\prime}$ & $1.88\left(\mathrm{~s}, 3 \mathrm{H}=\mathrm{CH}_{3}\right)$ & $1.88\left(\mathrm{~s}, 3 \mathrm{H}=\mathrm{CH}_{3}\right)$ \\
\hline $9^{\prime}$ & $2.28\left(\mathrm{~s}, 3 \mathrm{H}=\mathrm{CH}_{3}\right)$ & $2.28\left(\mathrm{~s}, 3 \mathrm{H}=\mathrm{CH}_{3}\right)$ \\
\hline $10^{\prime}$ & $2.28\left(\mathrm{~s}, 3 \mathrm{H}=\mathrm{CH}_{3}\right)$ & $2.28\left(\mathrm{~s}, 3 \mathrm{H}=\mathrm{CH}_{3}\right)$ \\
\hline $11^{\prime}$ & $4.25\left(\mathrm{~s}, 3 \mathrm{H}=\mathrm{OCH}_{3}\right)$ & $4.25\left(\mathrm{~s}, 3 \mathrm{H}=\mathrm{OCH}_{3}\right)$ \\
\hline 1" & $1.92\left(\mathrm{~s}, 3 \mathrm{H}=\mathrm{CH}_{3}\right)$ & $1.92\left(\mathrm{~s}, 3 \mathrm{H}=\mathrm{CH}_{3}\right)$ \\
\hline 2" & $1.92\left(\mathrm{~s}, 3 \mathrm{H}=\mathrm{CH}_{3}\right)$ & $1.92\left(\mathrm{~s}, 3 \mathrm{H}=\mathrm{CH}_{3}\right)$ \\
\hline
\end{tabular}

NMR, nuclear magnetic resonance.

\section{Compound elucidation using ${ }^{1} \mathrm{H}$ NMR}

The acetone extract of $C$. anisata leaves was subjected to column chromatography and TLC using a mobile phase of hexane: EtOAC (2:1, 1:1 and 1:2) and washed with $\mathrm{MeOH}$ to yield Fractions A-G. ${ }^{1} \mathrm{H}$ NMR results revealed that Fraction A, which was a yellowish oil, is a mixture of 5,7-disubstituted coumarin derivatives, which were found to be enantiomers $4 a-b$; NMR peak values are shown in Table 3 and the spectrum in Figure 4. The scientific name of the new compound isolated is (S/R)-3(1,1,3-trimethyl-2-butenyl)-5-(2,3-dihydroxy-3-methylbutane) -7-methyl-2H-1-benzopyran-2-one (Figure $5 \mathrm{~d}$ ), depending on the configuration of the function group at position $2^{\prime}$.

Compounds Compounds A and B (Figure 5) obtained from Fraction A are swiete coumarins, which are formed from anisocoumarin $\mathrm{A}$ in which the aldehyde group $(\mathrm{CHO})$ was oxidised into the group with asterisk $\left(^{*}\right)$. Compounds A and $B$ differ at position $6^{\prime}$. Because of the chiral centre at $2^{\prime}$, this newly isolated compound might display be peaks that are doubled (Figure 5).

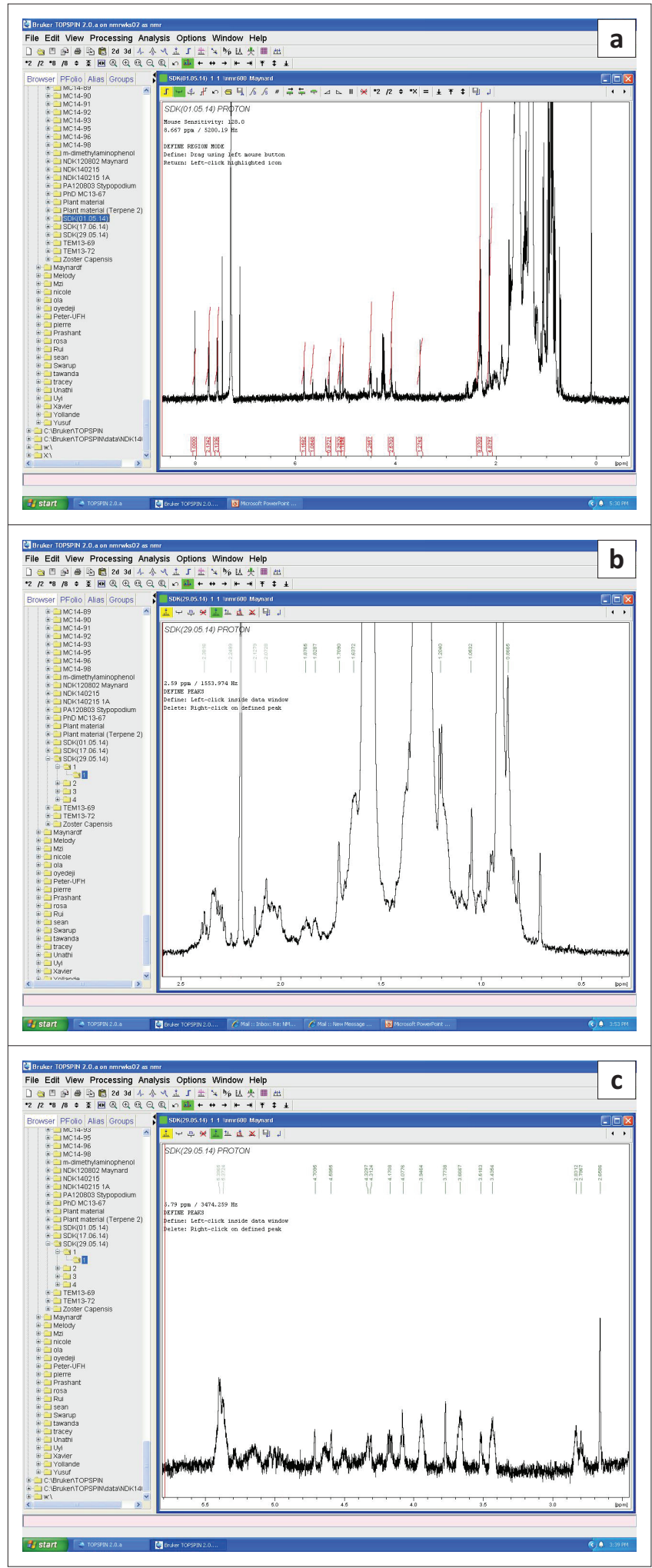

FIGURE 4: ${ }^{1} \mathrm{H}$ NMR spectrum of the isolated compounds. NMR, nuclear magnetic resonance.

\section{Compound identification using liquid chromatography-mass spectroscopy}

LC-MS is regarded as one of the best techniques to provide detailed information on targeted and non-targeted compound in natural products (Soam et al. 2013; Wolfender et al. 2003). The LC-MS results are presented in Figures 7 and 8 . 


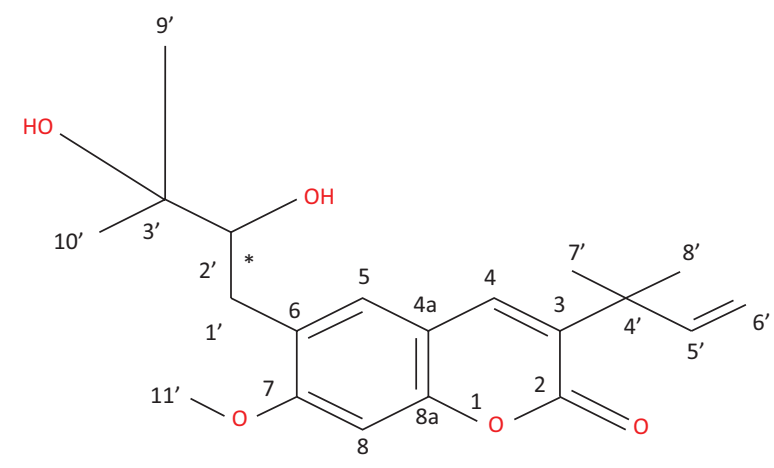

A

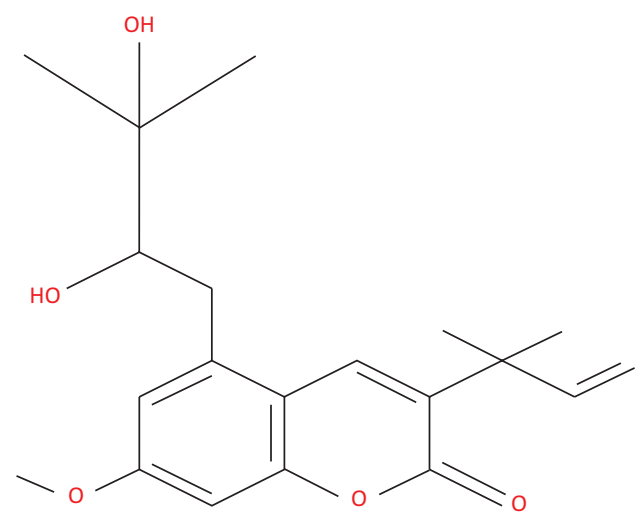

C

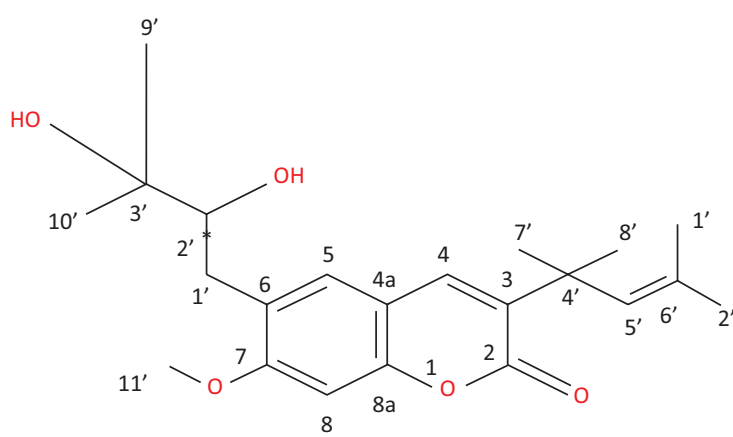

B

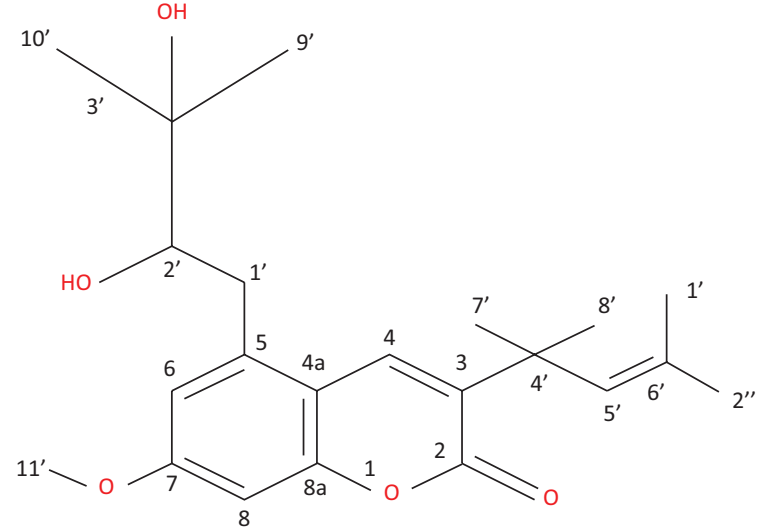

FIGURE 5: Compounds isolated from Fraction A of acetone extract of $C$. anisata: (A-C) coumarin derivatives, (D) (S/R)-3-(1,1,3-trimethyl-2-butenyl)-5-(2,3-dihydroxy-3methylbutane)-7-methyl-2H-1-benzopyran-2-one.

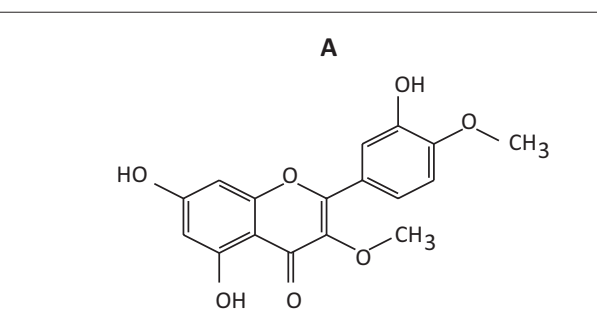

5,7-Dihydroxy-2-(3-hydroxy-4-methoxyphenyl)-3-methoxy-4Hchromen-4-one

3, 4'-dimethoxyquercetin (C17H14O7). MW: 330.0 Da

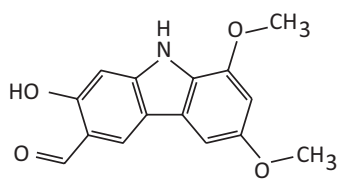

2-Hydroxy-6,8-dimetho xy-9H-carbaz ole-3carbaldehyde

Clausine $\mathrm{B}\left(\mathrm{C}_{15} \mathrm{H}_{13} \mathrm{NO}_{4}\right)$. MW: 271.0Da

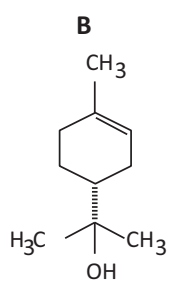

(R)-2-(4-met hylcyclohex-3-en-1-yl)propan-2-ol $\alpha$-Terpineol $\left(\mathrm{C}_{10} \mathrm{H}_{18} \mathrm{O}\right)$. MW: $154 \mathrm{Da}$

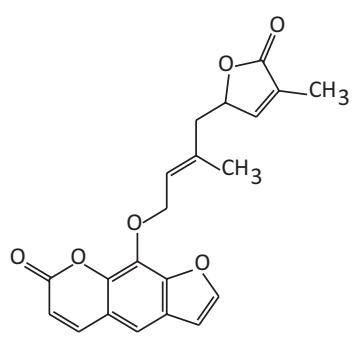

(E)-9-((3-Methyl-4-(4-methyl-5-oxo-2,5-dihydrofuran-2-yl) but-2-en-1-yl)oxy)-7H-furo[3,2-g]chromen-7-one

Clausenocoumarine $\left(\mathrm{C}_{12} \mathrm{H}_{18} \mathrm{O}_{6}\right)$. MW: $366.0 \mathrm{Da}$ 

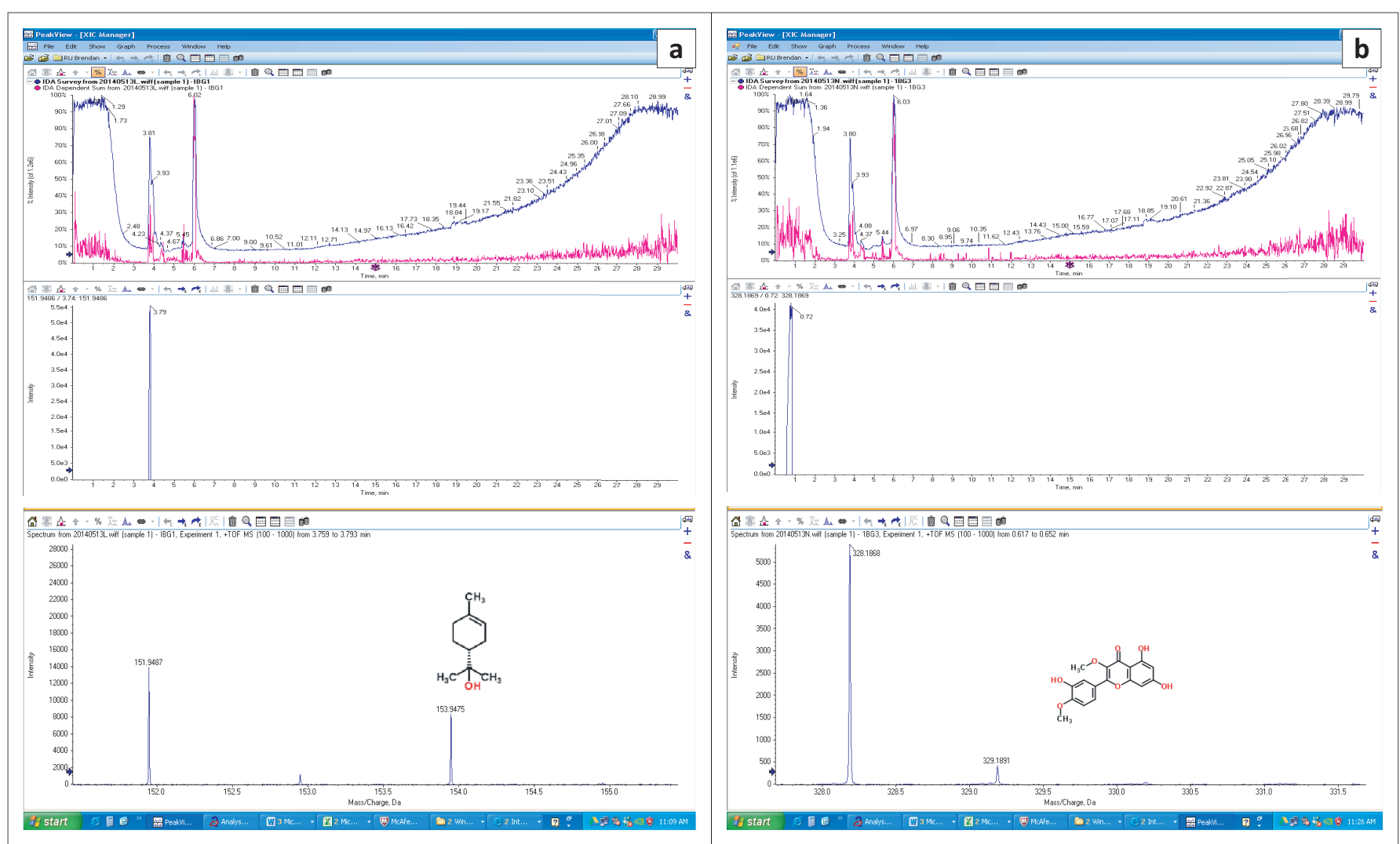

FIGURE 7: Liquid chromatography-mass spectroscopy chromatogram of clausine B and clausenocoumarine.
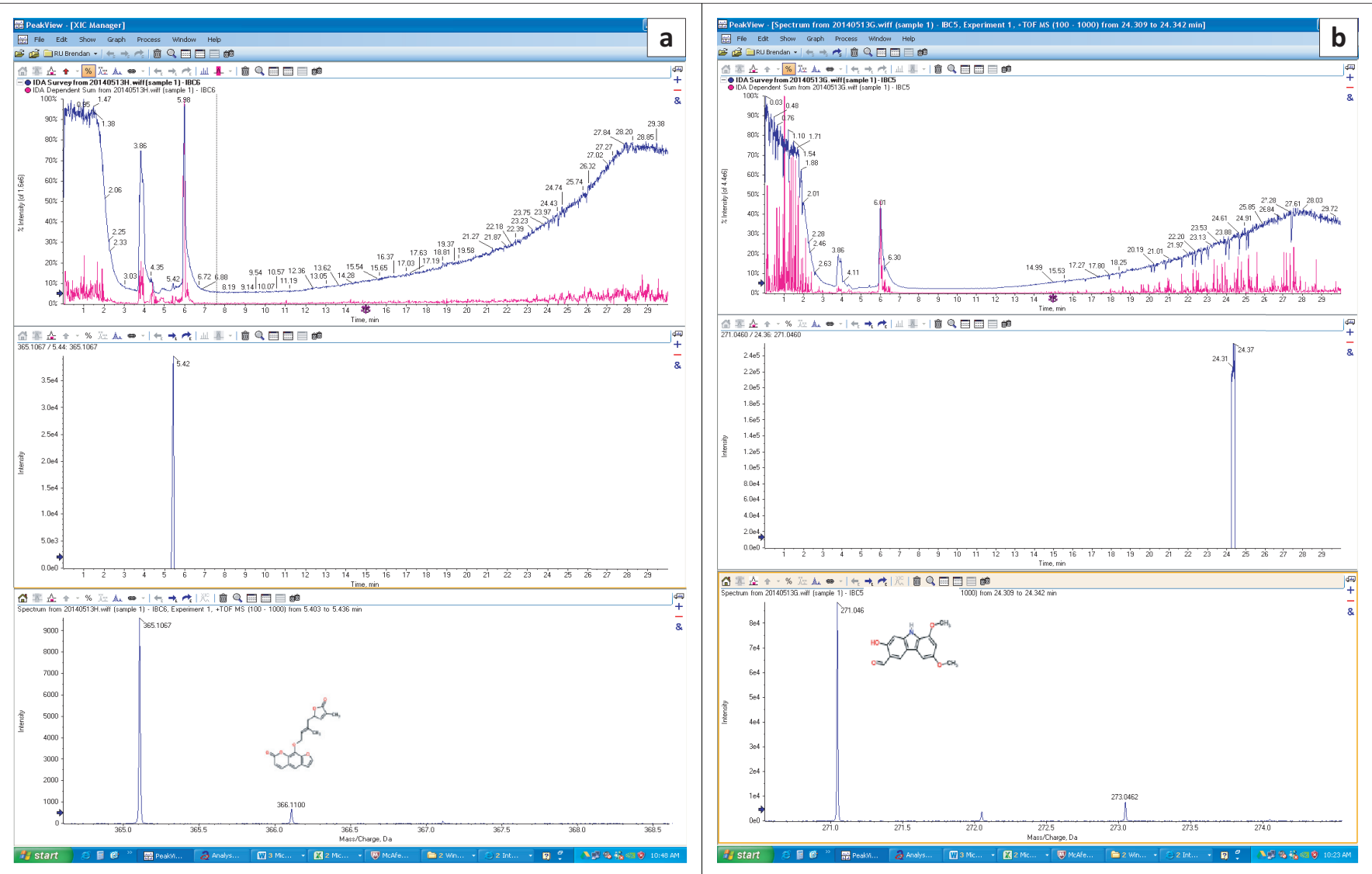

FIGURE 8: Liquid chromatography-mass spectroscopy chromatogram of quercetin 3,4-dimethyl ether and $\alpha$-terpineol. 
The following compounds were identified: Fraction C (clausine B), Fraction D (clausenocoumarin and $\alpha$-terpineol) and Fraction G (quercetin 3, 4-dimethyl ether) (Figure 6). These compounds were identified at different retention times and molecular weights. They are alkaloids and flavonoids, compounds isolated proven to be very active against the test bacteria; this is also in support of the previously reported potency of some alkaloid compounds and flavonoids isolated from plants against several diseases and health conditions such as tuberculosis, oxidative stress such as arthritis, fungal infections and inflammation. Clausine B and quercetin 3, 4-dimethyl ether have been previously isolated from Murraya koenigii and Dillenia indica, respectively (Chakarbotty, Barman \& Bose 1964; Gowsala \& Uvais 1975). However, these compounds were identified in the extract of $C$. anisata growing in South Africa using LC-MS profiling and were screened for their antibacterial activities using bioautography. Therefore, this study further supports the belief of the traditional healers and herbalists in the Eastern Cape using C. anisata for the management of some infectious diseases.

\section{Conclusion}

The isolated and identified compounds exhibited antibacterial activity against the test organisms as indicated in our results and discussion. Phytochemical screening of acetone leaf extract of $C$. anisata revealed the presence of saponins, tannins, alkaloids, flavonoids, phenolics and phytosteroids. With reference to the number of people using medicinal plants in South Africa, the search for new pharmacologically-active compounds with a standardised dosage is therefore imperative. Clausine B, clausenocoumarin, $\alpha$-terpineol and quercetin 3,4-dimethyl ether were identified in C. anisata and shown to possess antibacterial properties, while 3-(1,1,3-trimethyl-2butenyl)-5-(2,3-dihydroxy-3-methylbutane)-7-methyl-2H-1benzopyran-2-one was reported for the first time in C. anisata growing in South Africa. The investigation of its biological activities requires further investigation.

\section{Acknowledgements}

This work was supported by Govan-Mbeki Research and Development Centre of the University of Fort Hare. Special thanks to Prof. A. J. Afolayan (Research Professor and Head, Medicinal plants and Economic Development Research niche).

\section{Competing interests}

The authors declare that they have no financial or personal relationships which may have inappropriately influenced them in writing this article.

\section{Authors' contributions}

I.O.L. was responsible for the collection of plant materials within the study areas, carried out all the experiments, performed data analysis and drafted the manuscript. M.G. handled the spectral data collection and interpretation. P.O.O. edited the manuscript. All authors read and approved the final manuscript.

\section{References}

Agyepong, N., Agyare, C., Adarkwa-Yiadom, M. \& Gbedema, S.Y., 2014, 'Phytochemical investigation and anti-microbial activity of Clausena anisata (Willd), Hook', African Journal of Traditional Complementary Alternative Medicine 11(3), 200-209. https://doi.org/10.4314/ajtcam.v11i3.28

Al-Maliki, D.A.M., 2011, 'Isolation and identification of phenolic compounds from Elettaria cardamomum seeds and study of their medicinal activity against pathogenic bacteria of prostate gland', Journal of Missan Researches 8(15), 1-11.

Amoo, S.O., Ndhlala, A.R., Finnie, J.F. \& Van Staden, J., 2009, 'Antibacterial, antifungal and anti-inflammatory properties of Burchellia bubalina, South Africa', Journal of Botany 75(1), 60-63.

Boye, A. George, Koffuor, G. A., Boampong, J. N., Amoateng, P., A., Ameyaw, et al., 2012, 'Gastroprotective effect and safety assessment of Zanthoxylum zanthoxyloides (Lam) Waterm root bark extract' American Journal of Pharmacy and Toxicology 7(2), 73-80.

Buwa, L.V. \& Afolayan, A.J., 2009, 'Antimicrobial activity of some medicinal plants used for the treatment of tuberculosis in the Eastern Cape Province, South Africa', African Journal of Biotechnology 8(23), 6683-6687.

Chakraborty, A., Chowdhury, B.K. \& Bhattacharrya, P., 1995, 'Clausenol and clauseninetwo carbazole alkaloids from Clausena anisata', Phytochemistry 40(1), 295-298. https://doi.org/10.1016/0031-9422(95)00047-B

Chakarbotty, D.P., Barman, B.K. \& Bose, P.K., 1964, 'Structure of girinimbine, a pyranocarbazole derivative isolated from Murraya koenigii Spreng', Scientific Culture 30, 445-448.

Dai, J. \& Mumper, P.J., 2010, 'Plant phenolics: Extraction, analysis and their antioxidant and anticancer properties', Molecules 15, 7313-7352. https://doi.org/10.3390/ molecules15107313

Dubey, R., Dubey K., Sridhar C. \& Jayaveera, N., 2011, 'Human vaginal pathogen inhibition studies on aqueous, methanolic and saponins extracts of stem barks of Ziziphus mauritiana', International Journal of Pharmaceutical Sciences and Research 2(3), 659-663.

Eloff, J.N., 1998, 'A sensitive and quick method to determine the minimum inhibitory concentration of plant extracts for bacteria', Planta Medica 60, 1-8.

Eloff, J.N., 1999, 'The antibacterial activity of 27 southern African members of the Combretaceae', South African Journal of Science 95, 148-152.

Ghasemzadeh, A. \& Ghasemzadeh, N., 2011, 'Flavonoids and phenolic acids: Role and biochemical activity in plants and human', Journal of Medicinal Plants Research 5(31), 6697-6703. https://doi.org/10.5897/JMPR11.1404

Gowsala, P.M. \& Uvais, S.S., 1975, 'Chemical investigation of ceylonese plants. Part XII. (+)- 3,4',5,7 Tetrahydroxy-3'- methoxyflavanone [(+)- dihydroisorhamnetin] and 3,5,7-trihydroxy-3', $4^{\prime}$-dimethoxyflavone (dillenetin): Two new natural products from Dillenia indica L', Journal of Chemical Society, Perkin Transactions products

Grierson, D.S. \& Afolayan, A.J., 1999, 'An ethnobotanical study of plants used for the treatment of wounds in the Eastern Cape, South Africa', Journal of Ethnopharmacology 67, 327-332. https://doi.org/10.1016/S0378-8741(99)00082-3

Hamza, O.J., van den Bout-van den Beukel, C.J. \& Matee, M.I., 2006, 'Antifungal activity of some Tanzanian plants for the treatment of fungal infections', Journal of Ethnopharmacology 108, 124-132. https://doi.org/10.1016/j.jep.2006.04.026

Hutchings, A., Scoh, A.H., Lewis, G. \& Cunningham, A., 1996, Clausena anisata (Wild). Hook. F. ex Benth, Zulu medicinal plants: An inventory, University of Natal Press, Pietermaritzbury, South Africa Vol. 1, pp. 153-154.

Lawal, I.O., Grierson, D.S. \& Afolayan, A.J., 2014, 'Phytotherapeutic information on plants used for the treatment of tuberculosis in eastern Cape Province, South Africa', Evidence-Based Complementary and Alternative Medicine Article ID 735423, 11 pages, https://doi.org/10.1155/2014/735423

Lekganyane, M.A., Matsebatlela, T.M., Howard, R.L., Shai, L.J. \& Masoko, P., 2012, 'The phytochemical, antibacterial and antioxidant activity of five medicinal plants against the wound infecting bacteria', African Journal of Biotechnology 11(68), 13210-13219.

Levy, S.B. \& Marshall, B., 2004, 'Antibacterial resistance worldwide: Causes, challenges and responses', Nature Medicine 10,122-129. https://doi.org/10.1038/ $\mathrm{nm} 1145$

Maple, P. A., Hamilton-Miller, J. M. T. \& Brumfitt, W., 1989, 'World-wide antibiotic resistance in methicillin-resistant Staphylococcus aureus', Lancet 1(8637):537-40

Masika, P.J. \& Afolayan, A.J., 2003, 'An ethnobotanical study of plants used for the treatment of livestock diseases in the Eastern Cape Province, South Africa', Pharmaceutical Biology 41, 16-21. https://doi.org/10.1076/phbi.41.1.16 14694

Masoko, P. \& Nxumalo, K.M., 2013, 'Validation of antimycobacterial plants used by traditional healers in three districts of the Limpopo Province (South Africa)', Evidence-Based Complementary and Alternative Medicine 586247 (2013), 7.

Masoko, P., Picard, J. \& Eloff, N., 2005, 'Antifungal activities of six South African Terminalia species (Combretacea)', Journal of Ethnopharmacology 99, 301-308. https://doi.org/10.1016/j.jep.2005.01.061 
McGaw, L.J., Jager, A.K. \& Van Staden, J., 2002, 'Variation in antibacterial activity of Schotia species', South African Journal of Botany 68(1), 41-46. https://doi.org/ 10.1016/S0254-6299(16)30452-5

Moeng, T.A., 2010, 'An investigation into the trade of medicinal plants by muthi shops and street vendors in the Limpopo Province, South Africa', Msc (Botany) dissertation, University of Limpopo, Turfloop, South Africa (Unpublished).

Ojewole, J.A., 2002, 'Hypoglycaemic effect of Clausena anisata (Willd) Hook methanolic root extract in rats', Journal of Ethnopharmacology 81(2), 231-237. https://doi.org/10.1016/S0378-8741(02)00085-5

Omoruyi, B. E., Bradley, G. \& Afolayan, A. J., 2012, 'Antioxidant and phytochemical properties of Carpobrotus edulis (L.) bolus leaf used for the management of common infections in HIV/AIDS patients in Eastern Cape Province', BMC Complementary and Alternative Medicine 12, 215.

Parekh, J., Jadeja, D. \& Chanda, S., 2005, 'Efficacy of aqueous and methanol extracts of some medicinal plants for potential antibacterial activity', Turkish Journal of Biology 29, 203-210.

Raimondo, D., van Staden, L., Foden, W., Victor, J.E., Helme, N.A., Turner, R.C., et al., 2009, Red list of South African plants. Strelitzia 25, South African National Biodiversity Institute, Pretoria, pp.1-55.

Rashed, K.N. \& Butnariu, M., 2014, 'Isolation and antimicrobial and antioxidan evaluation of bio-active compounds from Eriobotrya Japonica stems', Advanced Pharmaceutical Bulletin 4(1), 75-81.

Sasidharan, S., Chen, Y., Saravanan, D., Sundram, K.M. \& Yoga Latha, L., 2011 'Extraction, isolation and characterization of bioactive compounds from plants' 'Extraction, isolation and characterization of bioactive compounds from plants' 8(1), $1-10$.

Schreiber, A., Cox, D., Pace, N. \& Borton, C., 2010, 'Metabolomic profiling of accurate mass LC-MS/MS data to identify unexpected environmental pollutants', Food and Environment 046210-02, 1-5.
Senthikumar, A. \& Venkatesalu, V., 2009, 'Phytochemical analysis and antibacterial activity of the essential oil of Clausena anisata (Willd.) hook. f. ex benth', International Journal of Integrative Biology 5, 116-120.

Shai, L.J. \& Eloff, J.N., 2009, 'Extracts of the leaves and twigs of the threatened tree Curtisia dentata (Cornaceae) are more active against Candida albicans and other microorganisms than the stem bark extract', South African Journal of Botany 75(2), 222-226. https://doi.org/10.1016/j.sajb.2008.11.008

Shriner, R., Fuson, R., Curtin, D. \& Morrill, T., 1979, The systematic identification of organic compounds, 6th ed., John Wiley and Sons NJ.

Soam, P.S., Singh, T., Vijayvergia, R. \& Jayabaskaran, C., 2013, 'Liquid chromatographymass spectrometry based profile of bioactive compounds of Cucumis callosus Europ', Journal of Experimental Biology 3(1), 316-326.

Songue, J.L., Kouam Dongo, E., Mpondo, T.N. \& White, R.L., 2014, 'Chemical constituents from stem bark and roots of Clausena anisata', Molecules 17 13673-13686. https://doi.org/10.3390/molecules171113673

Van Vuuren, S.F., 2007, 'The antimicrobial activity and essential oil composition of medicinal aromatic plants used in African traditional healing', PhD thesis, The University of the Witwatersrand, Gauteng, South Africa.

Van Wyk, B.E. \& Wink, M., 2004, Medicinal plants of the world, 1st edn., Briza Publication, Pretoria.

Watt, J.M. \& Breyer-Brandwijk, M.G., 1962, The medicinal and poisonous plants of southern and eastern Africa, Livingstone Ltd, Edinburgh.

Wolfender, J., Ndjoko, K. \& Hostettmann, K., 2003, 'A chromatographic technique of isolation of compounds in plants', Journal of Chromatography 1000, 437-455. https://doi.org/10.1016/S0021-9673(03)00303-0

York, T., van Vuuren, S.F. \& De Wet, H., 2012, 'An antimicrobial evaluation of plants used for the treatment of respiratory infections in rural Maputaland, KwaZuluNatal, South Africa', Journal of Ethnopharmacology 144, 118-127. https://doi. org/10.1016/j.jep.2012.08.038 